\title{
Role of SIRT1/AMPK signaling in the proliferation, migration and invasion of renal cell carcinoma cells
}

\author{
XIN WANG ${ }^{*}$, YOULU LU* ${ }^{*}$ ZHOUTING TUO*, HUAN ZHOU, YING ZHANG, \\ ZHANGJUN CAO, LONGFEI PENG, DEXIN YU and LIANGKUAN BI
}

Department of Urology, The Second Affiliated Hospital of Anhui Medical University, Hefei, Anhui 230032, P.R. China

Received November 15, 2020; Accepted March 5, 2021

DOI: 10.3892/or.2021.8060

\begin{abstract}
Renal cell carcinoma (RCC) is a lethal urologic tumor commonly seen in men that best responds to partial nephrectomy. An enhanced understanding of the molecular pathogenesis of RCC can broaden treatment options and tumor prevention strategies. Sirtuin 1 (SIRT1) is a NAD+-dependent deacetylase that regulates several bioactive substances, and the present study aimed to identify the role of SIRT1/AMP-activated protein kinase (AMPK) signaling in RCC progression. SIRT1 expression was detected in 100 patients with RCC using tissue microarray immunohistochemistry. SIRT1-knockdown and overexpression were performed via RNA interference and plasmid transfection. Inhibition of AMPK was used for the phenotypic rescue assays to verify whether AMPK was a downstream target of SIRT1. Reverse transcription-quantitative PCR was performed to verify transfection efficiency. Transwell, MTT and flow cytometry apoptosis assays were performed to evaluate the migration, invasion, proliferation and early apoptosis level of RCC cells. SIRT1 and AMPK protein expression in human RCC tissues and cell lines (786-O and ACHN) was detected using western blotting and immunofluorescence staining. The current results, combined with data from The Cancer Genome Atlas database, revealed that SIRT1 expression in RCC tissues was downregulated compared with in adjacent normal tissues. Additionally, high SIRT1 expression was associated with an improved prognosis in patients with RCC. Overexpression of SIRT1 inhibited the proliferation, migration and invasion
\end{abstract}

Correspondence to: Dr Liangkuan Bi, Department of Urology, The Second Affiliated Hospital of Anhui Medical University, 80 Feicui Road, Hefei, Anhui 230032, P.R. China

E-mail: biliangkuan118@yeah.net

*Contributed equally

Abbreviations: AMPK, AMP-activated protein kinase; OD, optical density; OS, overall survival; RCC, renal cell carcinoma; TCGA, The Cancer Genome Atlas; WHO/ISUP, World Health Organization/ International Society of Urologic Pathology; SIRT1, sirtuin 1

Key words: RCC, SIRT1, AMPK, prognosis of RCC cell lines and induced apoptosis, while inhibition of SIRT1 expression had the opposite effects. Further experiments indicated that SIRT1 may serve an anticancer role by upregulating the expression levels of downstream AMPK, thus revealing a potential therapeutic target for RCC.

\section{Introduction}

Renal cell carcinoma (RCC) is the most lethal urologic tumor, accounting for $2-3 \%$ of global adult malignancies in 2017, and the annual morbidity due to RCC is constantly rising $(1,2)$. RCC is two times more common in men than in women, and $\sim 50 \%$ of patients already have metastases at initial diagnosis (3-6). Clear cell RCC (ccRCC) originates from the proximal tubule of the kidney and is the most common subtype of RCC, accounting for 75-80\% of all cases (7-9). However, ccRCC is not sensitive to radiotherapy or chemotherapy, and the sensitivity of ccRCC to immunotherapy and targeted therapy remains to be studied (10-14). Thus, partial nephrectomy remains the best approach to treat localized tumors $(15,16)$. An enhanced understanding of the molecular pathogenesis of $\mathrm{RCC}$ is of great importance for formulating tumor prevention strategies and guiding clinical treatment (17-19).

Sirtuin 1 (SIRT1) is a NAD+-dependent deacetylase belonging to the mammalian homolog of yeast Sir2 protein that serves an important role in regulating several bioactive substances (20-23). The activity of SIRT deacetylase depends on the concentration of NAD+ in the cytoplasm, so that when the concentration of NAD+ increases, SIRT1 deacetylase activity also increases $(24,25)$. AMP-activated protein kinase (AMPK) is a key kinase involved in the regulation of cellular energy metabolism $(26,27)$. AMPK responds to the ratio of AMP/ATP in the cell and accordingly adjusts the activity of the enzyme to maintain an energy balance (28). SIRT1 is considered an upstream activator of AMPK, and AMPK is considered a downstream molecule of SIRT1, capable of regulating energy metabolism in apoptosis (29). Additionally, AMPK can enhance SIRT1 activity by increasing intracellular NAD+ levels, leading to the deacetylation and activation of the SIRT1 target protein, regulation of mitochondrial function and maintenance of energy balance $(30,31)$. Conversely, current evidence supports the opposite effect of SIRT1 as a tumor protein or tumor suppressor in different types of tumor (32-35). 
Thus, the present study aimed to investigate the role of SIRT1/AMPK signaling in RCC progression and the potential mechanisms of its involvement. It was hypothesized that SIRT1 may act as a tumor suppressor in RCC by increasing phosphorylated AMPK expression.

\section{Materials and methods}

Study design and patients. The present study evaluated 100 patients (mean age, 57.6 years; age range, 43-81 years) who underwent radical nephrectomy at The Second Affiliated Hospital of Anhui Medical University (Hefei, China) between July 2016 and October 2019. Patients who received chemotherapy or radiotherapy before surgery were excluded from analyses. In total, 100 cases of primary RCC tissues and matched adjacent normal tissues $(1 \mathrm{~cm}$ from the tumor margin) were obtained. After surgical resection, the tumor and adjacent normal tissues were collected and stored at $-80^{\circ} \mathrm{C}$ until use. The study was approved by the Institutional Research Ethics Committee of The Second Affiliated Hospital of Anhui Medical University, and written informed consent was obtained from all patients.

Tissue microarray (TMA) immunohistochemical analysis. Immunohistochemical staining was performed on tissue chips containing tumor and adjacent tissues from patients with RCC. Surgically resected tumor specimens were fixed with $10 \%$ neutral formalin and embedded in paraffin. The tissue block was then sliced into $3-\mu \mathrm{m}$-thick sections. The slices were heated at $60^{\circ} \mathrm{C}$ for $60-120 \mathrm{~min}$, then dewaxed in xylene, rehydrated with a series of graded ethanol and boiled in a pressure cooker in $0.01 \mathrm{M}$ citrate buffer ( $\mathrm{pH}$ 6.0) for $2 \mathrm{~min}$. Hydrogen peroxide $(0.3 \%)$ was used to block endogenous peroxide activity, and the sections were incubated with $10 \%$ normal goat serum (Gibco; Thermo Fisher Scientific, Inc.) in TBS with $0.5 \%$ Tween-20 for $1 \mathrm{~h}$ at room temperature to block non-specific binding. The primary antibody (anti-SIRT1; cat. no. ab110304; 1:30; Abcam) was incubated overnight at $4^{\circ} \mathrm{C}$. The biotin-labeled secondary antibody (cat. no. PV-6000; 1:500; OriGene Technologies, Inc.) was incubated at room temperature for $1 \mathrm{~h}$.

For quantitative scoring based on immunohistochemistry results (positive light microscope; magnification, $\mathrm{x} 400$; Zen blue 3.1 software; Zeiss AG), the scoring criteria were based on staining intensity ( 0 , no staining; 1 , weak staining; 2 , medium staining; and 3, strong staining) and the percentage of positively stained cells $(1, \leq 25 \% ; 2,26-50 \% ; 3,51-75 \%$; and $4,>75 \%)$. The final score was calculated by adding these two scores. Total score cut-offs of $\leq 4$ and $>4$ were used to divide patients into low and high SIRT1 expression groups, respectively.

Cell line and cell culture. The human RCC 786-O and ACHN cell lines were obtained from The Cell Bank of Type Culture Collection of The Chinese Academy of Sciences. The cells were cultured in RPMI-1640 medium supplemented with $10 \%$ FBS and 5\% penicillin and streptomycin (all Gibco; Thermo Fisher Scientific, Inc.) at $37^{\circ} \mathrm{C}$ in a $5 \% \mathrm{CO}_{2}$ incubator, and the medium was renewed every two days.

SIRT1 overexpression and RNA interference. SIRT1 overexpression plasmids ( 3 and $5 \mathrm{mg}$; OE-SIRT1) and empty vector
(OE-NC) (both from Shanghai GenePharma Co., Ltd.) were transfected into 786-O and ACHN cells for $20 \mathrm{~min}$ at room temperature using Lipofectamine ${ }^{\circledR} 2000$ transfection reagent (Beyotime Institute of Biotechnology) according to the manufacturer's instructions.

Small interfering RNA (siRNA) targeting SIRT1 (si-SIRT\#1, 5'-GGAGAUGAUCAAGAGGCAATT-3' and si-SIRT\#2, 5'-GGAAAUAUAUCCUGGACAATT-3'), AMPK (si-AMPK\#1, 5'-UGACCUCAACUACAUGGUUTT-'3 and si-AMPK\#2, 5'-GCGGGAAUCCAAAGGAUAATT-'3) and scrambled negative control (si-NC\#1, 5'-UUCUCCGAACGU GUCACGUTT-'3 and si-NC\#2, 5'-UUCUCCGAACGUGUC ACGUTT-'3) were also designed by Shanghai GenePharma Co., Ltd. 786-O and ACHN cells were cultured in a 6-well plate to $60 \%$ confluence, and were transfected with $50 \mathrm{nmol} / 1$ of designated siRNA using Lipofectamine 2000 transfection reagent at $37^{\circ} \mathrm{C}$ for $6 \mathrm{~h}$, according to the manufacturer's instructions. Western blotting and reverse transcription-quantitative (RT-q)PCR were used to detect gene knockout efficiency $48 \mathrm{~h}$ after transfection.

MTT assay. To assess cell proliferation, cells were plated into 96-well culture plates overnight at a density of $5 \times 10^{3}$ cells/well, and then overexpression, knockdown, and empty carrier models were constructed and then cultured for 24,48 or $72 \mathrm{~h}$. The control and transfected groups received the same amount of DMSO. Subsequently, $10 \mu \mathrm{l}$ MTT solution $(2.5 \mathrm{mg} / \mathrm{ml})$ was added to each well, and the cells were incubated at $37^{\circ} \mathrm{C}$ for $4 \mathrm{~h}$. DMSO $(150 \mu \mathrm{l})$ was added to dissolve the obtained crystals. The optical density (OD) value was measured at $570 \mathrm{~nm}$ using an enzyme labeling instrument (Thermo Fisher Scientific, Inc.). The cell proliferation inhibition rate was calculated using the following formula: (1-OD experimental group/OD control group) $\mathrm{x} 100 \%$.

Transwell assay. Cell migration and invasion assays were performed using Transwell chambers (Corning, Inc.). A total of $2 \times 10^{4} 786-\mathrm{O}$ and $\mathrm{ACHN}$ cells were resuspended in serum-free medium and added to the upper chambers, while medium containing $10 \%$ FBS was added to the bottom chambers. Transwell chambers coated with Matrigel for $5 \mathrm{~h}$ at $37^{\circ} \mathrm{C}$ were used for cell invasion. The cells were placed in an incubator at $37^{\circ} \mathrm{C}$ for $24 \mathrm{~h}$. Subsequently, the Transwell chambers were washed twice with PBS, fixed with $4 \%$ paraformaldehyde at room temperature for $25 \mathrm{~min}$, stained with $0.4 \%$ crystal violet staining solution for $5 \mathrm{~min}$ and rinsed with distilled water. Finally, the number of migrating or invading cells was counted using a light inverted microscope (magnification, x400; Olympus Corporation).

Apoptosis assay. Apoptosis analysis was performed using the Annexin V-FITC Apoptosis Detection kit (BD Biosciences). Briefly, cells were seeded in 6-well plates at a cell density of $10^{5}$ cells/well. Following overnight culture, cells were transfected as aforementioned for $24 \mathrm{~h}$. Cells from each group were collected and centrifuged at $1,000 \mathrm{x}$ g for $5 \mathrm{~min}$ at room temperature. After washing twice with PBS, the supernatant was discarded, and the cells were gently resuspended in $500 \mu \mathrm{l}$ binding buffer. After adding $5 \mu \mathrm{l}$ Annexin V-FITC, $10 \mu \mathrm{l}$ propidium iodide was further added and mixed. After incubation at 
room temperature in the dark for $15 \mathrm{~min}$, the cells were immediately subjected to detection by flow cytometry (NAVIOS; Beckman Coulter, Inc.) and analyzed using FlowJo VX 10.6.2 (FlowJo LLC).

Western blotting. The mashed tissues and cells were lysed in RIPA lysis buffer (150 mM NaCl, $0.5 \%$ sodium deoxycholate, $0.1 \%$ SDS, $1 \%$ Igepal, 50 mM Tris-HCl pH 8.0 and 2 mMEDTA) in an ice bath for $30 \mathrm{~min}$ and centrifuged at $18,000 \mathrm{x} \mathrm{g} \mathrm{rpm}$ for $30 \mathrm{~min}$ at $4^{\circ} \mathrm{C}$. The supernatant was stored at $-80^{\circ} \mathrm{C}$. A BCA kit was used to determine the protein concentration. The same amount of protein $(8 \mu \mathrm{g})$ was separated via $10 \%$ SDS-PAGE and transferred to a PVDF membrane. After the PVDF membrane was blocked in 5\% BSA (cat. no. 9048-46-8; Beijing Solarbio Science \& Technology Co., Ltd.) at room temperature for $1 \mathrm{~h}$, it was incubated with anti-SIRT1 (cat. no. 19A7AB4; 1:2,000; Abcam), anti-AMPK (cat. no. D63G4; 1:1,000; Cell Signaling Technology, Inc.), anti-phospho-AMPKa (cat. no. D4D6D; 1:1,000; Cell Signaling Technology, Inc.) and anti- $\beta$-actin antibodies (cat. no. T0022; 1:3,000; Affinity Biosciences) overnight at $4^{\circ} \mathrm{C}$. Subsequently, it was incubated with HRP-conjugated goat anti-rabbit IgG (cat. no. S0001) and goat anti-mouse IgG (cat. no. S0002) secondary antibodies (both 1:10,000; Affinity Biosciences) at room temperature for $1 \mathrm{~h}$. The color of the PVDF membrane was developed using an enhanced chemiluminescence kit (Thermo Fisher Scientific, Inc.), and the gray value was analyzed using ImageJ software (version 1.8.0; National Institutes of Health).

Cell immunofluorescence. A total of 10,000 cells were seeded on a glass slide in a 6-well plate. The next day, the cells were fixed with $4 \%$ paraformaldehyde at room temperature for $20 \mathrm{~min}$. Subsequently, they were permeabilized with $0.1 \%$ TBS-Triton (cat. no. T8200; Beijing Solarbio Science \& Technology Co., Ltd.) and blocked with $1 \%$ normal goat serum (cat. no. SL038; Beijing Solarbio Science \& Technology Co., Ltd.) at room temperature for $1 \mathrm{~h}$. The primary antibodies (anti-SIRT1 and anti-phospho-AMPKa; 1:100) were incubated overnight at $4^{\circ} \mathrm{C}$. The Cy3-labeled goat anti-mouse IgG (cat. no. A0521) and the FITC-labeled goat anti-rabbit IgG (cat. no. A0562) secondary antibodies (both 1:200; Beyotime Institute of Biotechnology) were incubated for $1 \mathrm{~h}$ at room temperature. Finally, DAPI staining was performed for $2 \mathrm{~min}$ at room temperature and observed under a fluorescence microscope (magnification, $\mathrm{x} 400$ ).

$R T$-qPCR. Total RNA was extracted using TRIzol ${ }^{\circledR}$ reagent (Invitrogen; Thermo Fisher Scientific, Inc.), and then reverse transcribed into cDNA using a reverse transcription kit (Takara Bio, Inc.), according to the manufacturer's instructions. Subsequently, the SYBR-Green Real-time Polymerase Chain Reaction kit (Takara Bio, Inc.) was used to perform qPCR using the CFX96 system (Bio-Rad Laboratories, Inc.). The thermocycling conditions were as follows: Denaturation at $95^{\circ} \mathrm{C}$ for $5 \mathrm{~min}$, followed by 35 cycles of denaturation at $95^{\circ} \mathrm{C}$ for $30 \mathrm{sec}$, annealing at $55^{\circ} \mathrm{C}$ for $30 \mathrm{sec}$ and extension at $72^{\circ} \mathrm{C}$ for $1 \mathrm{~min}$. The $2^{-\Delta \Delta \mathrm{Cq}}$ method (36) was used to calculate the changes in expression levels. All RT-qPCR data was normalized by comparison to an endogenous $\beta$-actin control sample. The following primers were used: SIRT1 forward,
5'-ATCTGACTTTGCTCCCCTTAACC-3' and reverse, 5'-GGGCCCTGGTTGCAAGA-3'; AMPK forward, 5'-CCC ACCATCACTCCATCTCT-3' and reverse, 5'-AGCCTGCTT GGCACACTTAT-3'; $\beta$-actin forward, 5'-TCCTTCCTGGGC ATGGAGT-3' and reverse, 5'-ACTGTGTTGGCGTACAGG TC-3'.

Data sets. The mRNA expression levels of SIRT1 were analyzed in different stages (stage I-V) of renal cell carcinoma using Gene Expression Profiling Interactive Analysis, based on thousands of samples data from The Cancer Genome Atlas (TCGA) database (http://gepia.cancer-pku.cn/index.html).

Statistical analysis. All experiments were performed independently three times. The experimental data are expressed as the mean \pm standard deviation. $\chi^{2}$ test and Fisher's exact test were used to assess the association between SIRT1 expression and clinicopathological characteristics of the patients with RCC. Overall survival (OS) was evaluated using the Kaplan-Meier method with the log-rank test. Paired Student's t-test was used to compare two paired groups (clinical tumor samples and adjacent normal tissues) and one-way ANOVA with Bonferroni post-hoc test was used to analyze the differences between $>2$ groups. All statistical analyses were performed using the SPSS 23.0 software package (IBM Corp.). $\mathrm{P}<0.05$ was considered to indicate a statistically significant difference.

\section{Results}

High SIRT1 expression is associated with a favorable prognosis in patients with RCC. All patients were pathologically confirmed to undergo radical resection for renal cancer. TMA immunohistochemical staining results revealed lower SIRT1 expression in clinical tumor samples than in adjacent normal tissues (Fig. 1A and D). A western blot assay using samples from 8 patients revealed similar results, indicating that SIRT1 expression in human renal carcinoma tissues was lower than that in normal kidney tissues (Fig. 1B and C). The clinical characteristics of the patients are shown in Table I. All patients had complete follow-up data (mean follow-up time, 47.5 months). The high and low SIRT1 expression groups comprised 46 and 54 patients, respectively. The Kaplan-Meier OS curves indicated significantly longer OS rates in the high SIRT1 expression group. In terms of tumor stage, the present statistical analysis revealed that the difference between the high- and low-expression groups was statistically significant (Table I). Low SIRT1 expression in RCC cells was positively associated with advanced clinical stage (Fig. 1F), higher World Health Organization/International Society of Urologic Pathology (WHO/ISUP) nuclear grade (37) and larger tumor size (Table I).

SIRT1 inhibits the proliferation, migration and invasion of $R C C$ cells in vitro. Of the two siRNA knockdown models, si-SIRT1\#1 and si-SIRT1\#2, it was observed that si-SIRT1\#1 had a higher knockdown efficiency in both 786-O and ACHN RCC cell lines (Fig. 2A). In addition, the overexpression model demonstrated that, compared with the OE-NC, SIRT1 overexpression was positively associated with the amount of transfected plasmid (3 and $5 \mathrm{mg}$; Fig. 2B). SIRT1 
Table I. Association between SIRT1 expression and clinical characteristics of patients with RCC $(\mathrm{n}=100)$.

\begin{tabular}{|c|c|c|c|c|}
\hline Clinical characteristic & $\mathrm{N}$ & High expression & Low expression & P-value \\
\hline Age, years & & & & 0.808 \\
\hline$\leq 50$ & 41 & 18 & 23 & \\
\hline$>50$ & 59 & 28 & 31 & \\
\hline Sex & & & & 0.752 \\
\hline Male & 43 & 19 & 24 & \\
\hline Female & 57 & 27 & 30 & \\
\hline Affected kidney & & & & 0.929 \\
\hline Left & 45 & 21 & 24 & \\
\hline Right & 55 & 25 & 30 & \\
\hline Tumor classification & & & & 0.629 \\
\hline $\mathrm{ccRCC}$ & 86 & 38 & 48 & \\
\hline $\mathrm{pRCC}$ & 10 & 6 & 4 & \\
\hline $\mathrm{cRCC}$ & 4 & 2 & 2 & \\
\hline WHO/ISUP grade & & & & 0.001 \\
\hline G1 & 28 & 23 & 5 & \\
\hline G2-G3 & 65 & 21 & 44 & \\
\hline G4 & 7 & 2 & 5 & \\
\hline Clinical stage & & & & 0.026 \\
\hline I & 78 & 41 & 37 & \\
\hline II & 17 & 4 & 13 & \\
\hline III-IV & 5 & 1 & 4 & \\
\hline Tumor size, $\mathrm{cm}$ & & & & 0.044 \\
\hline$<4$ & 46 & 30 & 16 & \\
\hline $4-7$ & 31 & 10 & 21 & \\
\hline$>7$ & 23 & 6 & 17 & \\
\hline
\end{tabular}

RCC, renal cell carcinoma; ccRCC, clear cell RCC; pRCC, papillary RCC; cRCC, chromophobe RCC; SIRT1, sirtuin 1; WHO/ISUP, World Health Organization/International Society of Urologic Pathology.

overexpression and knockdown models revealed that following SIRT1 overexpression, the proliferation, migration and invasion of RCC cells was inhibited, while SIRT1-knockdown enhanced the proliferation, migration and invasion of cancer cells (Fig. 2C-E). The current transfected RCC model exhibited differences in apoptosis, with increased early and late apoptotic cells following SIRT1 overexpression and decreased early and late apoptotic cells following SIRT1-knockdown; although no significant difference was observed following SIRT1 overexpression in 786-O cells, significant differences were observed for the other conditions (Fig. 2F).

AMPK expression in RCC cells is positively associated with SIRT1. Using western blotting and immunofluorescence staining, it was revealed that following SIRT1 overexpression, the levels of phosphorylated AMPK were significantly increased, while when SIRT1 was knocked down, the levels of phosphorylated AMPK were significantly decreased (Fig. 3A and B).

SIRT1 inhibits the proliferation, migration and invasion of RCC cells by targeting AMPK. In order to verify whether AMPK is a downstream target of SIRT1, phenotypic response tests were performed. First, the transfection efficiency of overexpressing SIRT1 and inhibiting AMPK expression was verified by RT-qPCR and western blotting (Fig. 4A-C). Si-AMPK\#1 and si-AMPK\#2 were used to interfere with AMPK expression, and since si-AMPK\#1 exhibited higher interference efficiency, it was used in subsequent experiments. Phenotypic rescue assays revealed that, in terms of phosphorylated AMPK protein expression, AMPK inhibition reversed the effect induced by SIRT1 overexpression (Fig. 4D). Additionally, MTT, Transwell and apoptosis assays demonstrated that after AMPK inhibition, the effects of SIRT1 overexpression on proliferation, invasion, migration and apoptosis of RCC cells were reversed (Fig. 4E-G), indicating that AMPK may be a downstream target of SIRT1.

\section{Discussion}

Previous studies $(38,39)$ have emphasized SIRT1 as a potential tumor suppressor protein to inhibit RCC tumorigenesis, but the role of SIRT1/AMPK signaling in RCC progression is yet to be clarified (40). The present study used western blotting and immunohistochemistry to detect the expression levels of SIRT1 in clinical samples, revealing lower SIRT1 expression 
A
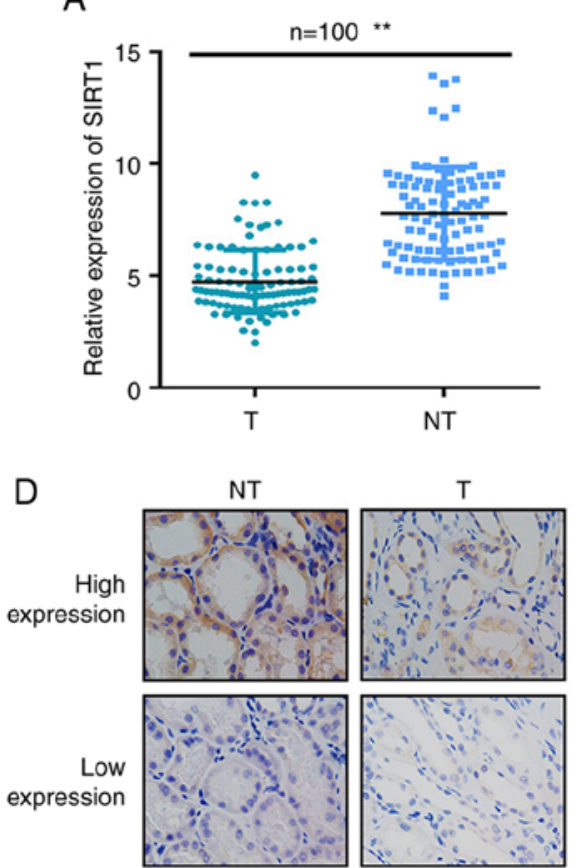

B
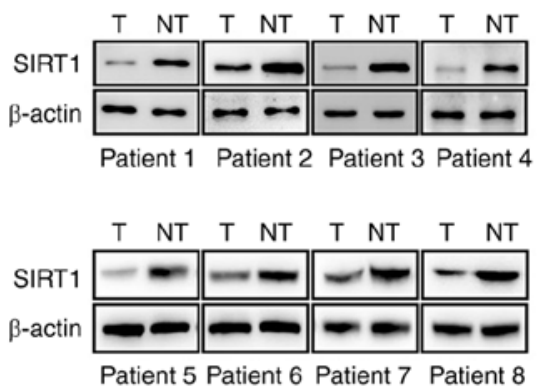

$\mathrm{E}$

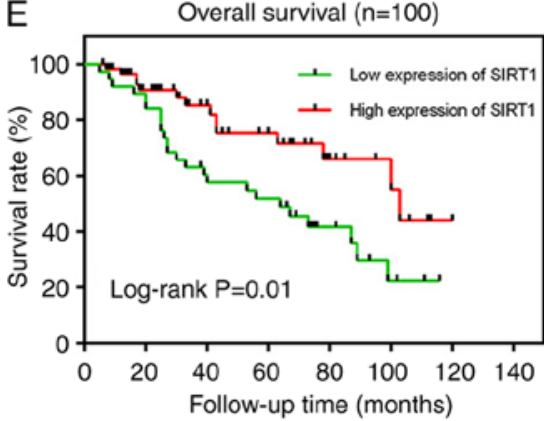

C
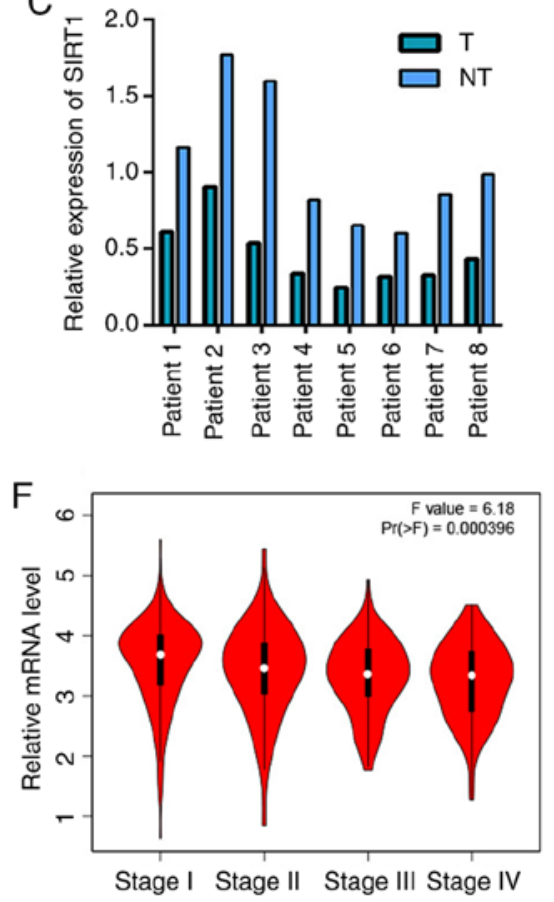

Figure 1. SIRT1 expression is downregulated in RCC tissues compared with in normal tissues, and high SIRT1 expression is associated with an improved prognosis. (A) Reverse transcription-quantitative PCR was used to detect SIRT1 expression in RCC and matched adjacent normal tissues, using $\beta$-actin as an endogenous control. (B and C) Protein expression levels of SIRT1 in 8 pairs of representative clinical specimens were measured by western blotting, using $\beta$-actin as an endogenous control. (D) Representative immunohistochemical images of SIRT1 staining in tumor and matched adjacent normal tissues (magnification, x400). (E) Kaplan-Meier overall survival curves according to SIRT1 expression in the study population. (F) SIRT1 expression at different tumor stages according to The Cancer Genome Atlas database. ${ }^{* *} \mathrm{P}<0.01$. RCC, renal cell carcinoma; T, tumor; NT, normal tissue; SIRT1, sirtuin 1.

in cancerous renal tissues than in normal renal tissues. Low SIRT1 expression in RCC tissues was associated with advanced clinical stage, higher WHO/ISUP nuclear grade and larger tumor size, which are negative prognostic features. The current results indicated that SIRT1 may serve a biological role in the development of RCC. Furthermore, a lower OS rate was associated with low SIRT1 expression than with high SIRT1 expression. Therefore, low SIRT1 expression indicated a poor prognosis in patients with RCC, consistent with the different expression levels of SIRT1 at different tumor stages according to TCGA database. However, previous studies have revealed that in esophageal squamous cell carcinoma and osteosarcoma, high SIRT1 expression is associated with a poor prognosis, which suggests that SIRT1 may serve different roles in different types of tumor (41-43).

SIRT1 is a type III histone deacetylase involved in regulating various physiological processes, including gene transcription, energy metabolism, cell cycle and apoptosis (44-47). Through TCGA database, it was revealed that among the numerous downstream signals of SIRT1, AMPK expression was closely associated with SIRT1 expression in kidney cancer (48). SIRT1 activation leads to deacetylation of lysine residues on liver kinase B1 (LKB1), which in turn enhances LKB1 kinase activity and leads to AMPK phosphorylation (49). Concurrently, the AMP/ATP ratio increases during insufficient cellular energy levels, subsequently activating AMPK (50). Activated AMPK increases the expression and activity of nicotinamide phosphoribosyl transferase, leading to an increase in NAD+ concentration, and further SIRT1 activation (51). Furthermore, the present results suggested that phosphorylated AMPK may have an anticancer role as a downstream target of SIRT1.

The present study used a plasmid transfection in vitro system to overexpress and knockdown SIRT1 in RCC cells. Results of Transwell and MTT assays revealed that the proliferation, migration and invasion of RCC cells were inhibited after SIRT1 overexpression, while knockdown of SIRT1 expression mediated the opposite effects. Apoptosis experiments indicated that in terms of early apoptosis, SIRT1 overexpression significantly promoted apoptosis in both cell lines. However, in terms of late apoptosis, the effect of SIRT1 overexpression in 786-O cells was not statistically significant. A previous study has revealed that SIRT1 may play a role by affecting the energy metabolism of tumor cells (52). AMPK is an enzyme closely associated with cell energy metabolism, and as a downstream molecule of SIRT1, it has a strong association with it in kidney cancer (53). Western blotting and immunofluorescence were used in the present study to confirm that when regulating SIRT1 expression, the levels of phosphorylated AMPK also changed in the same way. Therefore, the current results suggested that AMPK may act as a key downstream protein of SIRT1 to inhibit RCC cells.

Previous studies have revealed that AMPK activation directly phosphorylates its target proteins or transcriptionally controls its target genes, such as PGC1 $\alpha$ and p300 $(54,55)$. The present aforementioned results indicated that SIRT1 was positively associated with the levels of phosphorylated AMPK. The next step was to clarify whether AMPK is a downstream molecule of SIRT1 and the specific mechanism by which SIRT1 regulates AMPK. Therefore, a phenotypic 
A

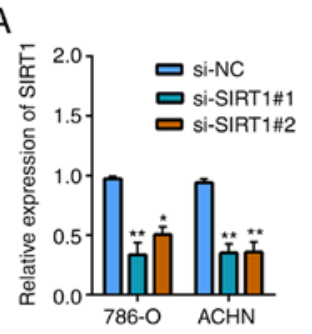

B

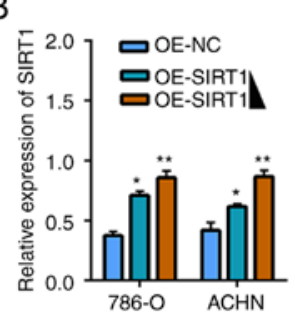

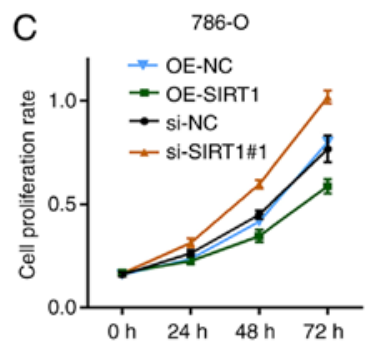

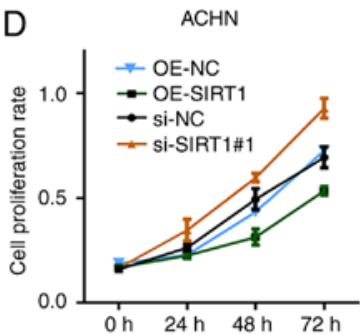

E
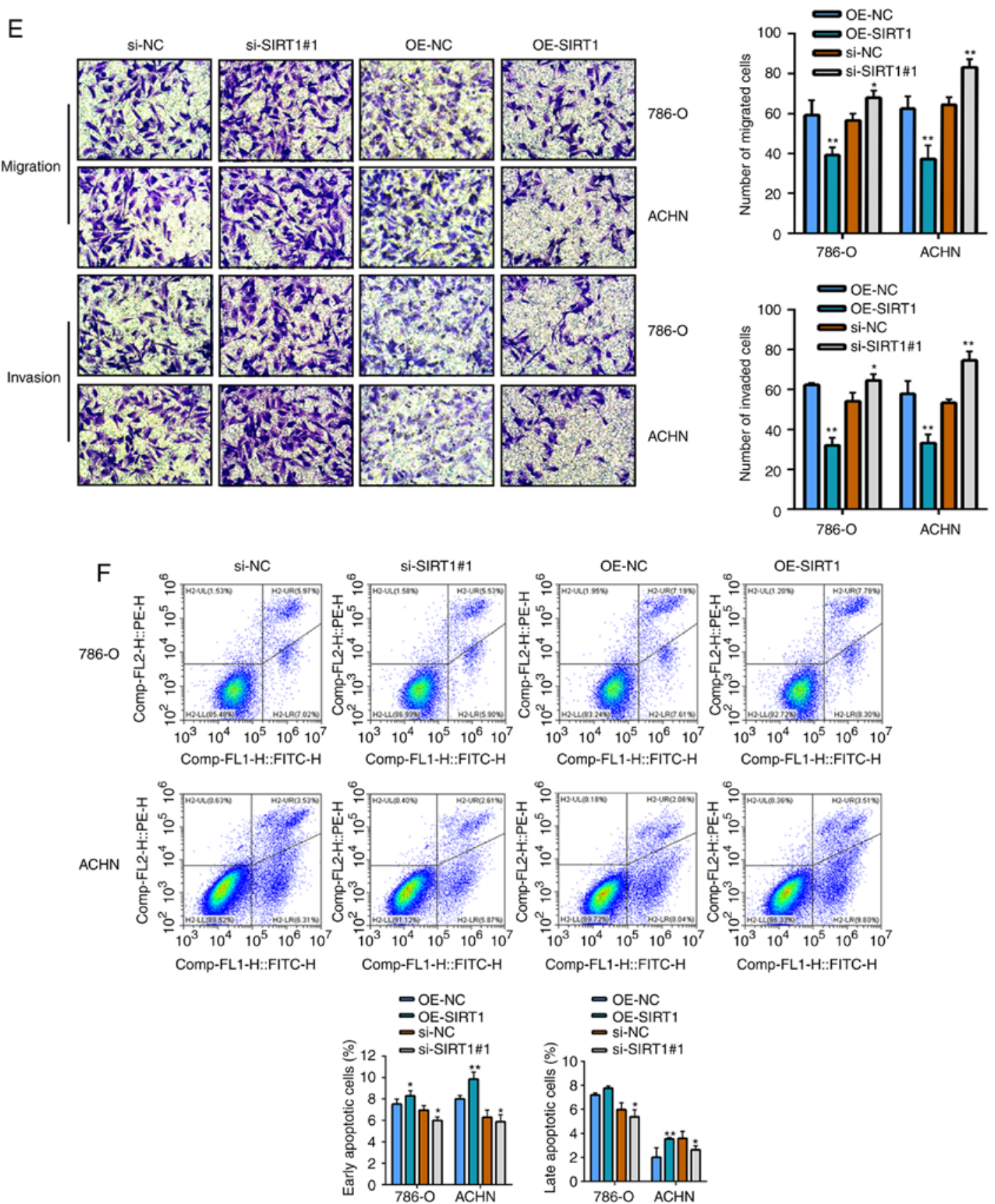

Figure 2. Regulation of SIRT1 expression affects the proliferation, migration, invasion and apoptosis of renal cell carcinoma cells. SIRT1 expression following its (A) knockdown and (B) overexpression in 786-O and ACHN cells as measured by reverse transcription-quantitative PCR (OE-SIRT1 3 and 5 mg). Proliferative ability of (C) 786-O and (D) ACHN cells transfected with si-SIRT1\#1, OE-SIRT1, si-NC or OE-NC as evaluated by MTT assay. (E) Cell migration and invasion in transfected cells as analyzed by Transwell assay (magnification, $\mathrm{x} 400$ ). (F) Apoptosis in transfected cells as evaluated by flow cytometry. ${ }^{*} \mathrm{P}<0.05$ and ${ }^{* *} \mathrm{P}<0.01$ vs. respective NC. OE, overexpression; NC, negative control; si, small interfering RNA; SIRT1, sirtuin 1.

rescue assay was designed to confirm the interference efficiency of AMPK siRNA, and revealed that AMPK inhibition reversed the increase in phosphorylated AMPK caused by overexpression of SIRT1. Using MTT and Transwell assays, it was confirmed that AMPK inhibition reversed the increase in cell proliferation, migration and invasion after 
A
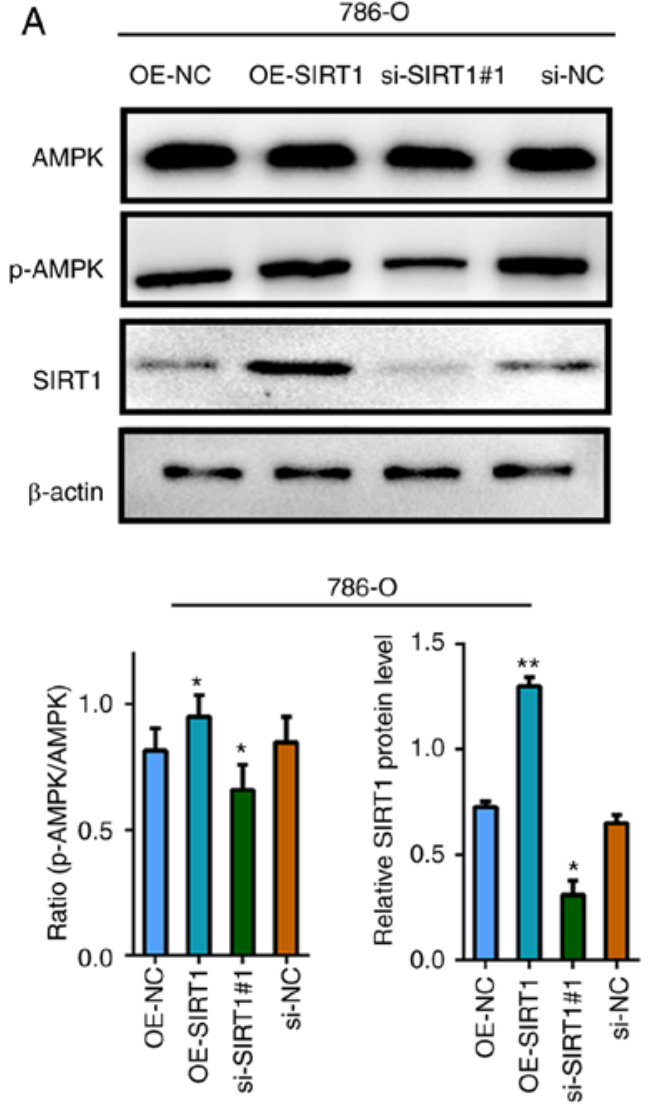
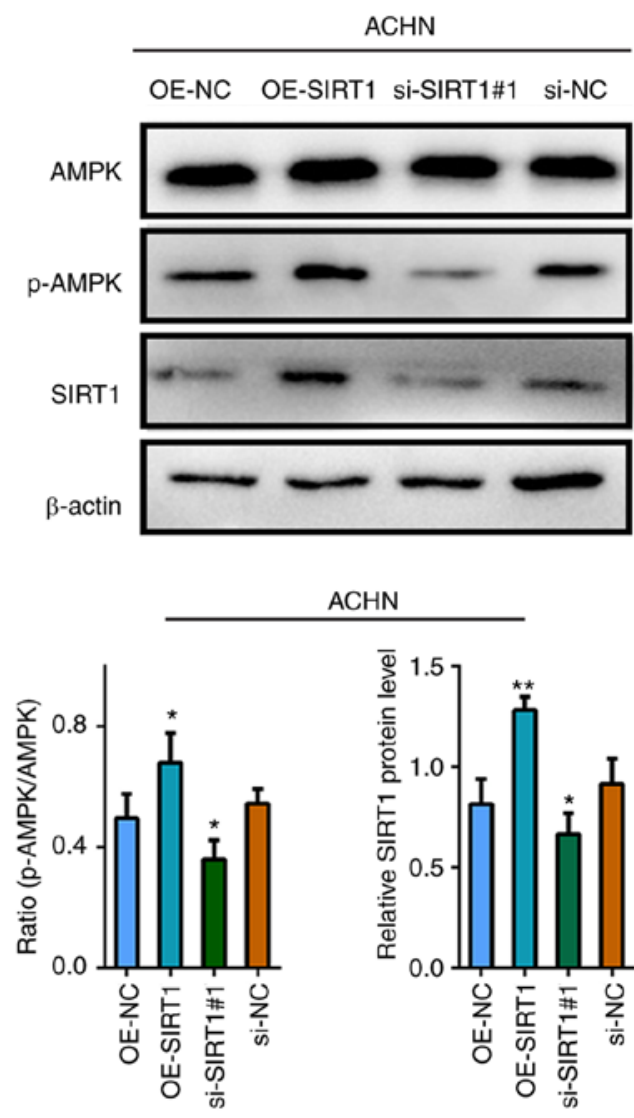

B

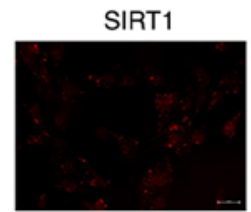

p-AMPK
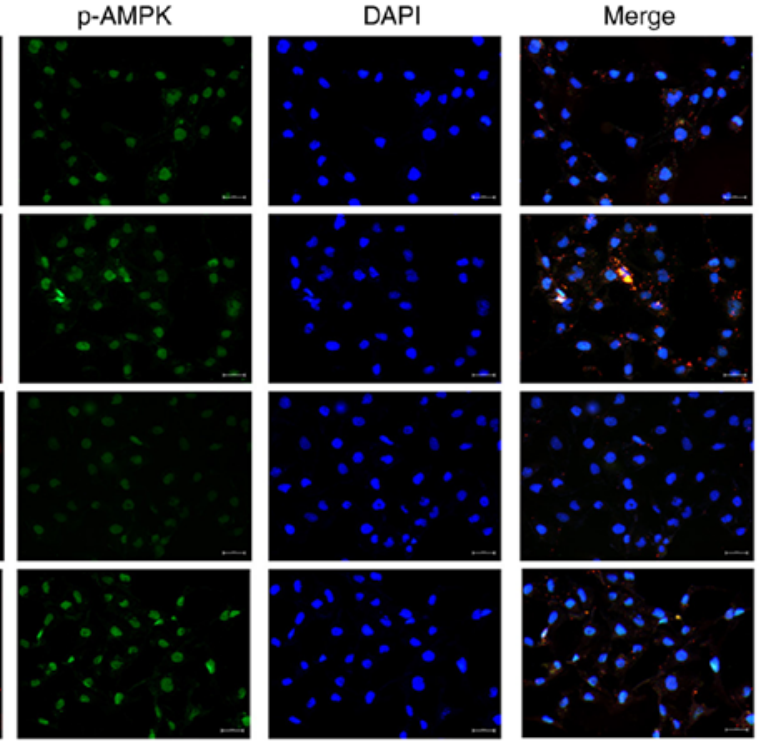

Figure 3. AMPK expression is positively associated with SIRT1 in RCC cells. (A) Western blotting and (B) cell immunofluorescence (magnification, x400) were used to detect the expression levels of SIRT1, AMPK and p-AMPK in RCC cells following SIRT1 overexpression or knockdown. "P<0.05 and ${ }^{* *} \mathrm{P}<0.01$ vs. respective NC. RCC, renal cell carcinoma; p, phosphorylated; AMPK, AMP-activated protein kinase; OE, overexpression; NC, negative control; si, small interfering RNA; SIRT1, sirtuin 1.

overexpression of SIRT1, suggesting that SIRT1 may regulate cell proliferation and migration through AMPK, and that AMPK may be a downstream target of SIRT1. Therefore, the current results suggested that the SIRT1/AMPK signaling pathway may serve as a potential therapeutic target in the treatment of kidney cancer. However, the sample size of the present study was limited and should be expanded for a deeper understanding of the mechanisms of SIRT1 in future studies.

In conclusion, SIRT1 expression was downregulated in RCC, and SIRT1 may serve an antitumor role by activating AMPK. Additionally, high SIRT1 expression predicted a favorable prognosis in patients with RCC. The current findings may help to develop new potential treatment strategies for RCC. 


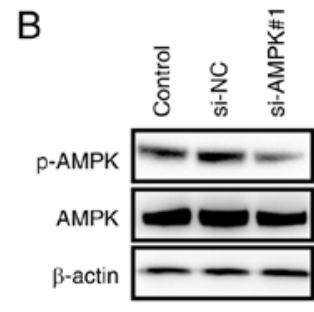

\section{A}

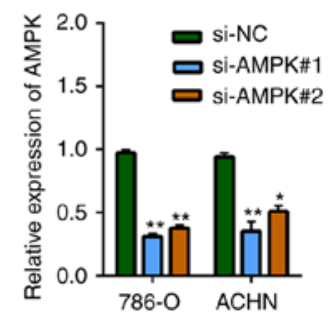

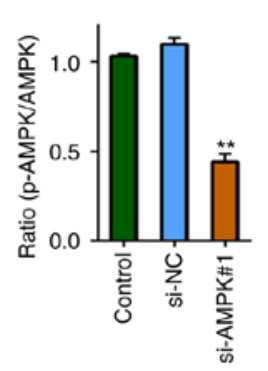
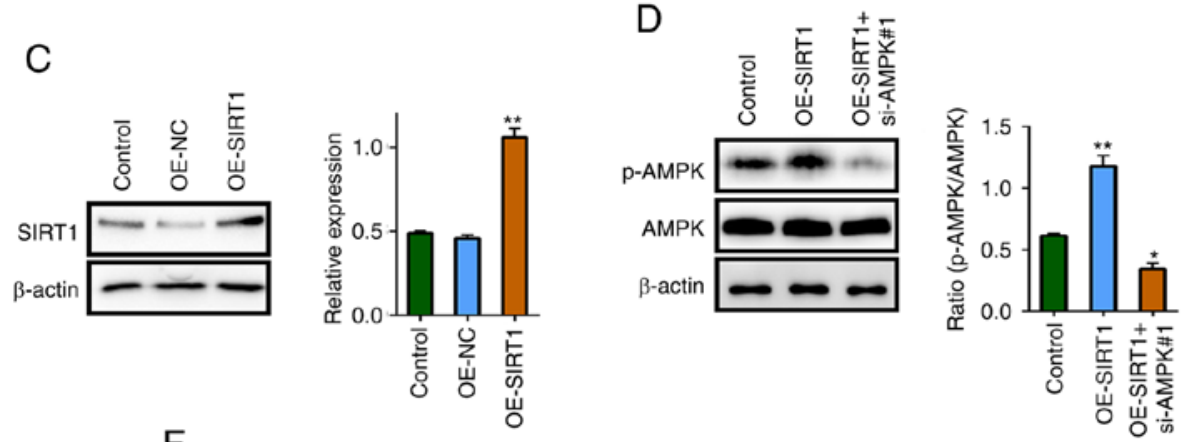

E $\rightarrow$ Control

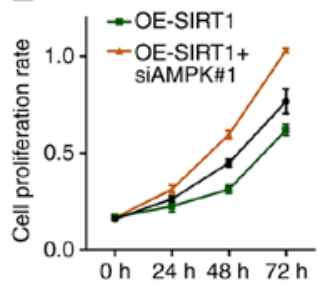

$\mathrm{F}$

OE-SIRT

OE-SIRT1+Si-AMPK\#1

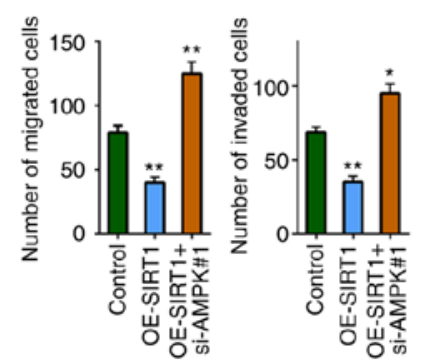

G
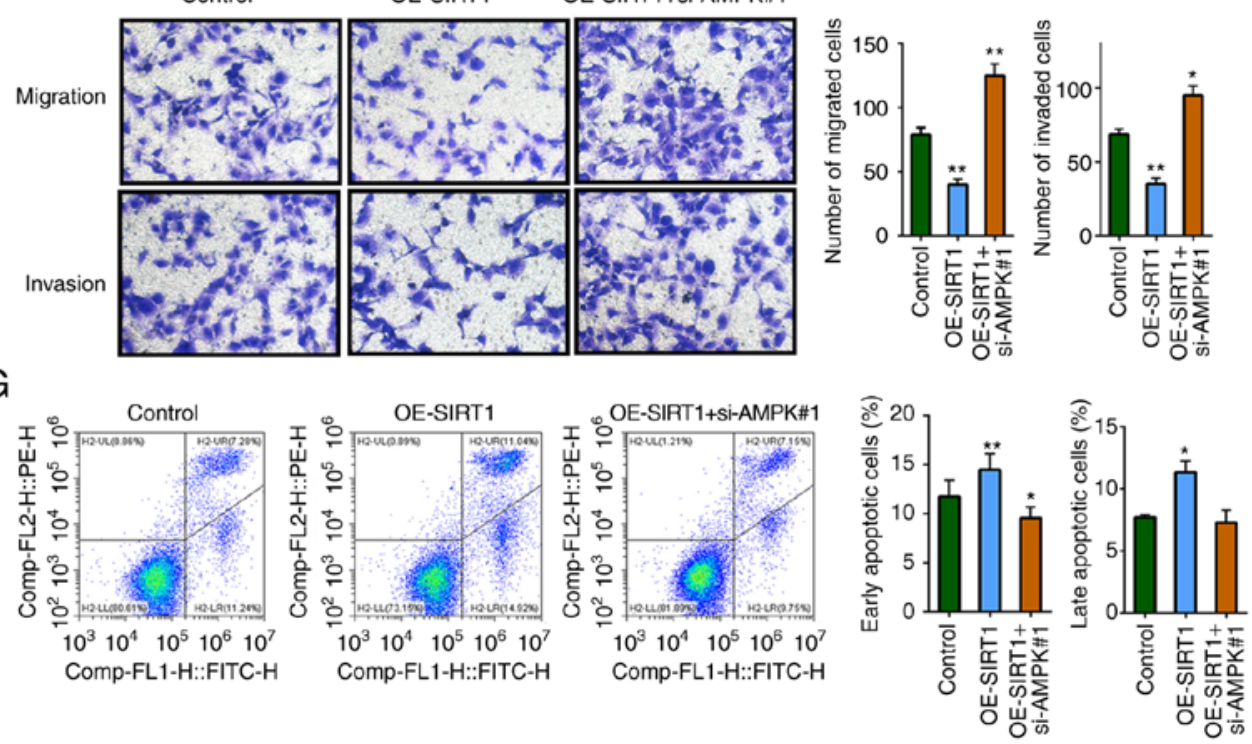

Figure 4. SIRT1 regulates the proliferation, migration and invasion of renal cell carcinoma cells by targeting AMPK. (A) Reverse transcription-quantitative PCR was performed to verify the transfection efficiency of AMPK siRNA (si-AMPK\#1 and si-AMPK\#2). Western blotting was used to assess (B) the levels of p-AMPK following AMPK inhibition and (C) SIRT1 expression following SIRT1 overexpression. (D) Differences in protein expression levels following SIRT1 overexpression and AMPK inhibition were detected via western blotting in 786-O cells. (E) MTT, (F) Transwell (magnification, $\mathrm{x} 400)$ and (G) apoptosis assays were performed to detect differences in the proliferation, migration, invasion and apoptosis of cells after AMPK inhibition in 786-O cells with SIRT1 overexpression. " $\mathrm{P}<0.05$ and ${ }^{* *} \mathrm{P}<0.01$ vs. respective NC or control. p, phosphorylated; AMPK, AMP-activated protein kinase; OE, overexpression; NC, negative control; si, small interfering RNA; SIRT1, sirtuin 1.

\section{Acknowledgements}

Not applicable.

\section{Funding}

The present study was supported by the National Natural Science Foundation of China (grant no. 81572507).

\section{Availability of data and materials}

The datasets used and/or analyzed during the current study are available from the corresponding author on reasonable request.
The datasets generated and/or analyzed during the current study are available in The Cancer Genome Atlas repository (http://gepia.cancer-pku.cn/index.html).

\section{Authors' contributions}

XW conceived and designed the study, wrote the original draft and acquired the data. YL acquired the data and was involved in drafting the manuscript. ZT statistically analyzed the data and revised it critically for important intellectual content. LB contributed to conceiving the study and gave final approval of the version to be published. YZ made substantial contributions to study design and acquisition of data, and was involved 
in drafting the manuscript. HZ contributed to analyzing and interpreting the data, and critically revised the manuscript for important intellectual content. ZC made substantial contributions to conception and design of the study, and statistically analyzed the data. LP analyzed the data and was involved in drafting the manuscript. DY contributed to conception and design of the study, and revised it critically for important intellectual content. XW and LB are responsible for confirming the authenticity of the data. All authors read and approved the final manuscript.

\section{Ethics approval and consent to participate}

The study was approved by the Institutional Research Ethics Committee of The Second Affiliated Hospital of Anhui Medical University (Hefei, China), and written informed consent was obtained from all patients.

\section{Patient consent for publication}

Not applicable.

\section{Competing interests}

The authors declare that they have no competing interests.

\section{References}

1. Siegel RL, Miller KD and Jemal A: Cancer Statistics, 2017. CA Cancer J Clin 67: 7-30, 2017.

2. Rini BI, Campbell SC and Escudier B: Renal cell carcinoma. Lancet 373: 1119-1132, 2009

3. Gumz ML, Zou H, Kreinest PA, Childs AC, Belmonte LS, LeGrand SN, Wu KJ, Luxon BA, Sinha M, Parker AS, et al: Secreted frizzled-related protein 1 loss contributes to tumor phenotype of clear cell renal cell carcinoma. Clin Cancer Res 13: 4740-4749, 2007.

4. Bao Y, Wang Z, Liu B, Lu X, Xiong Y, Shi J, Li P, Chen J, Zhang Z, Chen M, et al: A feed-forward loop between nuclear translocation of CXCR4 and HIF- $1 \alpha$ promotes renal cell carcinoma metastasis. Oncogene 38: 881-895, 2019.

5. Haber T, Jöckel E, Roos FC, Junker K, Prawitt D, Hampel C, Thüroff JW and Brenner W; German Renal Cell Tumor Network: Bone metastasis in renal cell carcinoma is preprogrammed in the primary tumor and caused by AKT and Integrin $\alpha 5$ Signaling. J Urol 194: 539-546, 2015.

6. Zhang Y, Thayele Purayil H, Black JB, Fetto F, Lynch LD, Masannat JN and Daaka Y: Prostaglandin E2 receptor 4 mediates renal cell carcinoma intravasation and metastasis. Cancer Lett 391: 50-58, 2017.

7. DeSantis CE, Lin CC, Mariotto AB, Siegel RL, Stein KD, Kramer JL, Alteri R, Robbins AS and Jemal A: Cancer treatment and survivorship statistics, 2014. CA Cancer J Clin 64: 252-271, 2014.

8. Obeng RC, Arnold RS, Ogan K, Master VA, Pattaras JG, Petros JA and Osunkoya AO: Molecular characteristics and markers of advanced clear cell renal cell carcinoma: Pitfalls due to intratumoral heterogeneity and identification of genetic alterations associated with metastasis. Int J Urol 27: 790-797, 2020.

9. Xue YJ, Chen SN, Chen WG, Wu GQ, Liao YF, Xu JB, Tang H, Yang SH, He SY, Luo YF, et al: Cripto-1 expression in patients with clear cell renal cell carcinoma is associated with poor disease outcome. J Exp Clin Cancer Res 38: 378, 2019.

10. Kasuya G, Tsuji H, Nomiya T, Makishima H, Haruyama Y, Kobashi G, Ebner DK, Hayashi K, Omatsu T, Kishimoto R, et al: Updated long-term outcomes after carbon-ion radiotherapy for primary renal cell carcinoma. Cancer Sci 109: 2873-2880, 2018.

11. Zhang Q, Shi J, Yuan F, Wang H, Fu W, Pan J, Huang Y, Yu J, Yang $\mathrm{J}$ and Chen Z: Higher expression of XPF is a critical factor in intrinsic chemotherapy resistance of human renal cell carcinoma. Int J Cancer 139: 2827-2837, 2016.
12. Diamond E, Molina AM, Carbonaro M, Akhtar $\mathrm{NH}$, Giannakakou P, Tagawa ST and Nanus DM: Cytotoxic chemotherapy in the treatment of advanced renal cell carcinoma in the era of targeted therapy. Crit Rev Oncol Hematol 96: 518-526, 2015.

13. Rini BI, Battle D, Figlin RA, George DJ, Hammers H, Hutson T, Jonasch E, Joseph RW, McDermott DF, Motzer RJ, et al: The society for immunotherapy of cancer consensus statement on immunotherapy for the treatment of advanced renal cell carcinoma (RCC). J Immunother Cancer 7: 354, 2019.

14. Bhindi B, Habermann EB, Mason RJ, Costello BA, Pagliaro LC, Thompson RH, Leibovich BC and Boorjian SA: Comparative survival following initial cytoreductive nephrectomy versus initial targeted therapy for metastatic renal cell carcinoma. J Urol 200: 528-534, 2018.

15. Gershman B, Thompson RH, Boorjian SA, Lohse CM, Costello BA, Cheville JC and Leibovich BC: Radical versus partial nephrectomy for cT1 renal cell carcinoma. Eur Urol 74: 825-832, 2018

16. Tabayoyong W, Abouassaly R, Kiechle JE, Cherullo EE, Meropol NJ, Shah ND, Dong S, Thompson RH, Smaldone MC, Zhu $\mathrm{H}$, et al: Variation in surgical margin status by surgical approach among patients undergoing partial nephrectomy for small renal masses. J Urol 194: 1548-1553, 2015.

17. Weiss J, Notohamiprodjo M, Bedke J, Nikolaou $K$ and Kaufmann S: Imaging response assessment of immunotherapy in patients with renal cell and urothelial carcinoma. Curr Opin Urol 28: 35-41, 2018.

18. Caliò A, Harada S, Brunelli M, Pedron S, Segala D, Portillo SC, Magi-Galluzzi C, Netto GJ, Mackinnon AC and Martignoni G: TFEB rearranged renal cell carcinoma. A clinicopathologic and molecular study of 13 cases. Tumors harboring MALAT1-TFEB, ACTB-TFEB, and the novel NEAT1-TFEB translocations constantly express PDL1. Mod Pathol 34: 842-850, 2021.

19. de Velasco G, Culhane AC, Fay AP, Hakimi AA, Voss MH, Tannir NM, Tamboli P, Appleman LJ, Bellmunt J, Kimryn Rathmell W, et al: Molecular subtypes improve prognostic value of International Metastatic Renal Cell Carcinoma Database Consortium Prognostic Model. Oncologist 22: 286-292, 2017.

20. Vaziri H, Dessain SK, Ng Eaton E, Imai SI, Frye RA, Pandita TK Guarente L and Weinberg RA: hSIR2(SIRT1) functions as an NAD-dependent p53 deacetylase. Cell 107: 149-159, 2001.

21. Stamatovic SM, Martinez-Revollar G, Hu A, Choi J, Keep RF and Andjelkovic AV: Decline in Sirtuin-1 expression and activity plays a critical role in blood-brain barrier permeability in aging. Neurobiol Dis 126: 105-116, 2019.

22. Islam S, Uehara O, Matsuoka H, Kuramitsu Y, Adhikari BR, Hiraki D, Toraya S, Jayawardena A, Saito I, Muthumala M, et al: DNA hypermethylation of sirtuin 1 (SIRT1) caused by betel quid chewing-a possible predictive biomarker for malignant transformation. Clin Epigenetics 12: 12, 2020.

23. Ming M, Zhao B, Shea C, Shea CR, Shah P, Qiang L, White SR, Sims DM and He YY: Loss of sirtuin 1 (SIRT1) disrupts skin barrier integrity and sensitizes mice to epicutaneous allergen challenge. J Allergy Clin Immunol 135: 936-945.e4, 2015.

24. Kalous KS, Wynia-Smith SL, Olp MD and Smith BC: Mechanism of Sirt1 NAD+-dependent protein deacetylase inhibition by Cysteine S-Nitrosation. J Biol Chem 291: 25398-25410, 2016.

25. Chandrasekaran K, Anjaneyulu M, Choi J, Kumar P, Salimian M, Ho CY and Russell JW: Role of mitochondria in diabetic peripheral neuropathy: Influencing the NAD-dependent SIRT1-PGC-1 $\alpha$-TFAM pathway. Int Rev Neurobiol 145: 177-209, 2019.

26. Okamoto S, Asgar NF, Yokota S, Saito K and Minokoshi Y: Role of the $\alpha 2$ subunit of AMP-activated protein kinase and its nuclear localization in mitochondria and energy metabolism-related gene expressions in C2C12 cells. Metabolism 90: 52-68, 2019.

27. Kanazawa I, Takeno A, Tanaka KI, Notsu M and Sugimoto T: Osteoblast AMP-activated protein kinase regulates glucose metabolism and bone mass in adult mice. Biochem Biophys Res Commun 503: 1955-1961, 2018.

28. Jiang S, Wang Y, Luo L, Shi F, Zou J, Lin H, Ying Y, Luo Y, Zhan Z, Liu P, et al: AMP-activated protein kinase regulates cancer cell growth and metabolism via nuclear and mitochondria events. J Cell Mol Med 23: 3951-3961, 2019.

29. Hou X, Xu S, Maitland-Toolan KA, Sato K, Jiang B, Ido Y, Lan F, Walsh K, Wierzbicki M, Verbeuren TJ, et al: SIRT1 regulates hepatocyte lipid metabolism through activating AMP-activated protein kinase. J Biol Chem 283: 20015-20026, 2008. 
30. Bae UJ, Park J, Park IW, Chae BM, Oh MR, Jung SJ, Ryu GS, Chae SW and Park BH: Epigallocatechin-3-Gallate-Rich Green tea extract ameliorates fatty liver and weight gain in mice fed a high fat diet by activating the Sirtuin 1 and AMP activating protein kinase pathway. Am J Chin Med 46: 617-632, 2018

31. Shentu TP, He M, Sun X, Zhang J, Zhang F, Gongol B, Marin TL, Zhang J, Wen L, Wang Y, et al: AMP-Activated Protein Kinase and Sirtuin 1 Coregulation of cortactin contributes to endothelial function. Arterioscler Thromb Vasc Biol 36: 2358-2368, 2016.

32. Chou X, Ding F, Zhang X, Ding X, Gao H and Wu Q: Sirtuin-1 ameliorates cadmium-induced endoplasmic reticulum stress and pyroptosis through XBP-1s deacetylation in human renal tubular epithelial cells. Arch Toxicol 93: 965-986, 2019.

33. Guo H, Ding H, Tang X, Liang M, Li S, Zhang J and Cao J: Quercetin induces pro-apoptotic autophagy via SIRT1/AMPK signaling pathway in human lung cancer cell lines A549 and H1299 in vitro. Thorac Cancer: May 11, 2021 (Epub ahead of print). doi: 10.1111/1759-7714.13925.

34. Subbaramaiah K, Iyengar NM, Morrow M, Elemento O, Zhou XK and Dannenberg AJ: Prostaglandin $\mathrm{E}_{2}$ down-regulates sirtuin 1 (SIRT1), leading to elevated levels of aromatase, providing insights into the obesity-breast cancer connection. J Biol Chem 294: 361-371, 2019.

35. George J, Nihal M, Singh CK and Ahmad N: 4'-Bromo-resveratrol, a dual Sirtuin-1 and Sirtuin-3 inhibitor, inhibits melanoma cell growth through mitochondrial metabolic reprogramming. Mol Carcinog 58: 1876-1885, 2019.

36. Livak KJ and Schmittgen TD: Analysis of relative gene expression data using real-time quantitative PCR and the 2(-Delta Delta C(T)) method. Methods 25: 402-408, 2001

37. Warren AY and Harrison D: WHO/ISUP classification, grading and pathological staging of renal cell carcinoma: Standards and controversies. World J Urol 36: 1913-1926, 2018.

38. Miranda-Gonçalves V, Lameirinhas A, Macedo-Silva C, Lobo J, C Dias P, Ferreira V, Henrique R and Jerónimo C: Lactate increases renal cell carcinoma aggressiveness through Sirtuin 1-dependent epithelial mesenchymal transition axis regulation. Cells 9: 1053, 2020.

39. Jeh SU, Park JJ, Lee JS, Kim DC, Do J, Lee SW, Choi SM, Hyun JS, Seo DH, Lee C, et al: Differential expression of the sirtuin family in renal cell carcinoma: Aspects of carcinogenesis and prognostic significance. Urol Oncol 35: 675.e9-675.e15, 2017.

40. Chen Y, Zhu Y, Sheng Y, Xiao J, Xiao Y, Cheng N, Chai Y, Wu X, Zhang S and Xiang T: SIRT1 downregulated FGB expression to inhibit RCC tumorigenesis by destabilizing STAT3. Exp Cell Res 382: 111466, 2019.

41. Feng H, Guo P, Wang J, Xu J, Xie C and Gao F: Expression of Leptin and Sirtuin-1 is associated with poor prognosis in patients with osteosarcoma. Pathol Res Pract 212: 319-324, 2016.

42. Yan L, Zhao Q, Liu L, Jin N, Wang S and Zhan X: Expression of SIRT1 and survivin correlates with poor prognosis in esophageal squamous cell carcinoma. Medicine (Baltimore) 99: e21645, 2020.

43. Chung SY, Jung YY, Park IA, Kim H, Chung YR, Kim JY, Park SY, Im SA, Lee KH, Moon HG, et al: Oncogenic role of SIRT1 associated with tumor invasion, lymph node metastasis, and poor disease-free survival in triple negative breast cancer. Clin Exp Metastasis 33: 179-185, 2016.
44. Dong YJ, Liu N, Xiao Z, Sun T, Wu SH, Sun WX, Xu ZG and Yuan H: Renal protective effect of sirtuin 1. J Diabetes Res 2014: 843786, 2014

45. Zhang X, Chen J, Sun L and Xu Y: SIRT1 deacetylates KLF4 to activate Claudin-5 transcription in ovarian cancer cells. J Cell Biochem 119: 2418-2426, 2018.

46. Atkins KM, Thomas LL, Barroso-González J, Thomas L, Auclair S, Yin J, Kang H, Chung JH, Dikeakos JD and Thomas G: The multifunctional sorting protein PACS-2 regulates SIRT1-mediated deacetylation of p53 to modulate p21-dependent cell-cycle arrest. Cell Rep 8: 1545-1557, 2014.

47. Han Y, Luo H, Wang H, Cai J and Zhang YJ: SIRT1 induces resistance to apoptosis in human granulosa cells by activating the ERK pathway and inhibiting NF- $\kappa \mathrm{B}$ signaling with anti-inflammatory functions. Apoptosis 22: 1260-1272, 2017.

48. Tang Z, Li C, Kang B, Gao G, Li C and Zhang Z: GEPIA: A web server for cancer and normal gene expression profiling and interactive analyses. Nucleic Acids Res 45: W98-W102, 2017.

49. Fu H, Song W, Chen X, Guo T, Duan B, Wang X, Tang Y, Huang L and Zhang C: MiRNA-200a induce cell apoptosis in renal cell carcinoma by directly targeting SIRT1. Mol Cell Biochem 437: $143-152,2018$

50. Kahn BB, Alquier T, Carling D and Hardie DG: AMP-activated protein kinase: Ancient energy gauge provides clues to modern understanding of metabolism. Cell Metab 1: 15-25, 2005.

51. Wang LF, Wang XN, Huang CC, Hu L, Xiao YF, Guan XH, Qian YS, Deng KY and Xin HB: Inhibition of NAMPT aggravates high fat diet-induced hepatic steatosis in mice through regulating Sirt1/AMPKa/SREBP1 signaling pathway. Lipids Health Dis 16: 82, 2017.

52. Dong HW, Zhang LF and Bao SL: AMPK regulates energy metabolism through the SIRT1 signaling pathway to improve myocardial hypertrophy. Eur Rev Med Pharmacol Sci 22: 2757-2766, 2018

53. Tian L, Cao W, Yue R, Yuan Y, Guo X, Qin D, Xing J and Wang X: Pretreatment with Tilianin improves mitochondrial energy metabolism and oxidative stress in rats with myocardial ischemia/reperfusion injury via AMPK/SIRT1/PGC-1 alpha signaling pathway. J Pharmacol Sci 139: 352-360, 2019.

54. Wang L, Quan N, Sun W, Chen X, Cates C, Rousselle T, Zhou X, Zhao X and Li J: Cardiomyocyte-specific deletion of Sirtl gene sensitizes myocardium to ischaemia and reperfusion injury. Cardiovasc Res 114: 805-821, 2018.

55. Cao Y, Bojjireddy N, Kim M, Li T, Zhai P, Nagarajan N, Sadoshima J, Palmiter RD and Tian R: Activation of $\gamma 2$-AMPK suppresses ribosome biogenesis and protects against myocardial ischemia/reperfusion injury. Circ Res 121: 1182-1191, 2017.

This work is licensed under a Creative Commons Attribution-NonCommercial-NoDerivatives 4.0 International (CC BY-NC-ND 4.0) License. 